\title{
RESEARCH ON CARBON EMISSION DIVERSITY FROM THE PERSPECTIVE OF URBANIZATION
}

\author{
ZHENG, D. C. ${ }^{1,2}-$ LIU, W. X. ${ }^{1,2, *}-$ LI, X. X. ${ }^{1}-$ LIN, Z. Y. ${ }^{1}-$ JIANG, H. ${ }^{2}$ \\ ${ }^{1}$ Internet Innovation Research Center-The College's Research Base of Humanities and Social \\ Science in Fujian Province, Minjiang University, 350108 Fuzhou, Fujian, China \\ ${ }^{2}$ Straits Institute of Minjiang University, 350108 Fuzhou, Fujian, China \\ *Corresponding author \\ e-mail: 424070881@qq.com; phone: +86-136-8500-6093 \\ (Received $1^{\text {st }}$ Jul 2018; accepted $13^{\text {th }}$ Sep 2018)
}

\begin{abstract}
Urbanization is only a carrier of human activities, and it does not directly affect carbon emissions. Based on the essential relationship of carbon emissions and urbanization, and summarizing the shortcomings of the present research methods, this paper first classifies the degree of urbanization in China by using the multi-index cluster analysis method based on panel data, and then analyzes the influence factors of carbon emissions by the STIRPAT model for different urbanization levels. The results show that the elasticity of factors affecting carbon emissions is quite different under different urbanization levels. The conclusion is that the policy of reducing emissions should be different for different levels of urbanization. Differentiated emission reduction policies are necessary for a vast China. Keywords: classification of urbanization, factors of carbon emission, STIRPAT model, entropy weight, multi-index cluster analysis
\end{abstract}

\section{Introduction}

At present, the greenhouse effect has seriously affected the global climate and has become a serious obstacle in the process of human social development, and carbon dioxide is the most important component of greenhouse gases, and its contribution to the greenhouse effect is more than $60 \%$. It can be seen that the excessive emission of carbon dioxide is the main reason for the greenhouse effect.

Scholars have started a lot of work around the causes of excessive carbon dioxide emissions. They have analyzed the possible factors, including economic growth, income level, industrial structure and so on, and the degree of urbanization is also regarded as an important factor. However, in most of the research work, "urbanization" is regarded as an explanatory variable into the model, which is a one-sided approach. In essence, the extent of carbon emissions depends on changes in human activities. Urbanization is a carrier of changes in human activities, affecting human activities, but it does not directly affect carbon emissions.

Based on the essential relationship between carbon emission and urbanization and the shortcomings of current research methods, the degree of urbanization in China is classified by using the multi-index cluster analysis method based on panel data. The influence factors of carbon emissions are analyzed through the STIRPAT model, and it is found that under different levels of urbanization, the influence of various factors on carbon emissions is quite different. The conclusion is that for provinces and cities with different urbanization levels, the emission reduction policy should be different, and for a vast China, differentiated emission reduction policies are very necessary. 


\section{Basic conception}

First of all, the scientific connotation of "urbanization" should be clarified. Cities and towns are only one of the geographic carriers of human activities where people form unique production mode, consumption mode and social mode. In a narrow sense, urbanization is a process of increasing urban population. However, urbanization in a broad sense is a trend of gradual change from a traditional rural society dominated by agriculture to a modern urban society dominated by industry and service industries. It includes the changes in the occupation of the population, the transformation of the industrial structure, and the changes in land and geographical space ( $\mathrm{Lu}, 2007)$. Urbanization is not only a simple migration of rural population to towns, but also a change in social structure (Poumanyvong and Kaneko, 2010). This is a dynamic process, manifested in the transformation of people in the geographical space of towns and villages. Therefore, using only the proportion of urban population does not fully describe the degree of urbanization.

The level and speed of urbanization are affected and restricted by the socio-economic environment and the natural environment. As Knox and McCarthy (2011) pointed out, "Urbanization is the interaction of a variety of factors, including economic, demographic, political, cultural, technological, environmental, and social, and it is also influenced by two kinds of contingency factors, such as geographical location and historical reasons."(Paraschiv, 2012). Therefore, in different countries and regions, the level and speed of urbanization show great differences.

Urbanization also plays an important role in ecological and social activities, making the natural environment and social environment change. These effects are positive and reverse. On the one hand, urbanization has brought about the increase of urban population, aggravated social and economic activities, resulting in greater demand for energy. At the same time, congested traffic brings congestion on the road. These two factors will cause serious air pollution and waste discharge. On the other hand, urbanization has produced an "agglomeration effect", which has concentrated the scope of social and economic activities and increased public transport at the same time. This can effectively reduce carbon emissions from commutes. Towns and cities are often centers of technological innovation, new technologies and new industries. The birth of these products can often increase production efficiency and reduce unit energy consumption, which can also effectively reduce carbon emissions.

\section{Literature review}

There is a correlation between urbanization and carbon emissions, which has become the consensus of researchers and policy makers. A large amount of research work has focused on the impact of urbanization on carbon emissions. If the impact of urbanization is neglected in the prediction of $\mathrm{CO}_{2}$ emissions and the formulation of energy and environmental policies, the model's forecast results and the effect of the implementation of policies will be seriously affected, and even result in a deviation in the direction of work (Sadorsky, 2014).

The ecological modernization theory founded by Joseph Huber and Martin Jänicke in Germany in the early 1980s pointed out that the ecological environment is inevitably affected by socio-economic activities, and that can be transformed from negative to positive in the process of economic development and social system transformation. Specifically, excessive carbon emissions are unavoidable in the primary and secondary 
stages of development. However, with the further advancement of modernization, the improvement of social environmental awareness, the innovation and application of environmental protection technologies, the scientific nature of urban planning and the adjustment of industrial structure, these factors will all contribute to the reduction of carbon emissions. Sun et al. (2013) studied the total carbon emissions of 76 countries and regions from 1980 to 2007, examined the relationship between the dynamic evolution of urbanization and carbon emissions, and verified the rationality of ecological modernization theory.

The theory of urban environmental change has put forward the opposite view, which is established on the base of a series of researches (Bartone et al., 1994; Lee, 1994; McGranahan et al., 1996; Pugh, 1996; Satterthwaite, 1997). McGranahan (2000) summed up these research results and developed this theory (Marcotullio and Lee, 2003). From the perspective of urban development, these scholars point out that the environmental problems faced by cities are different at each stages of development. Only in the middle and later stages of urban development can carbon emissions become one of the main problems of urban environment.

The problem of urban density was originally concerned by architecture and urban planning. When economists are involved in this field, how urban density affects environmental changes and energy consumption has become an interesting and practical topic, which has evolved a compact city theory. Most scholars supported the idea that compacting cities can bring environmental benefits. They believe that compact cities can bring about the scale effects of urban public facilities such as public transportation, public education and water supply. At the same time, compact cities can also reduce the use of private cars, shorten travel distances, and reduce losses in the power supply, thereby reducing energy consumption and $\mathrm{CO}_{2}$ emissions. However, some other critics pointed out that compact cities are more likely to cause new problems such as traffic jams and urban heat island effects, resulting in increased $\mathrm{CO}_{2}$ emissions (Gaigné et al., 2012).

Although the impact of urbanization on carbon emissions has become an important research area for urban economics, in most research work, the level of urbanization is simply measured by the proportion of urban population, and directly enters the model as an explanatory variable (Shahbaz et al., 2016; Yang et al., 2018), which does not accurately portray the true relationship between urbanization and carbon emissions. First, urbanization embodies a comprehensive process of change, and it is not enough to measure only the proportion of urban population. Secondly, using the urbanization level as an explanatory variable directly into the analysis model does not meet the true relationship between the two. The impact of urbanization on carbon emissions plays a role through human activities, and urbanization itself does not have a direct impact on environmental change.

The lack of research has attracted the attention of a few researchers who have put forward new ideas for research. Chikaraishi pointed out in the 2015 study that the relationship between urbanization and environmental change can be described by two relationships: indirect effect and moderating effect. He expressed the two effects by functions as follows: $y=f(\beta, x(z))$ and $y=f(\beta(z), x)$, where y indicates environmental change, $\mathrm{x}$ indicates human activity, $\mathrm{z}$ indicates urbanization degree, and $\beta$ indicates the influence of human activities on environmental changes. In the two functions, the former indicates that the explanatory variables (human activities) are influenced by the degree of urbanization, and the latter indicates that the degree of 
urbanization affects the elastic coefficient of human activity - environmental change. And the above three modern urban environmental theories have realized that the impact of urbanization on the environment may have both positive or reverse effects, which means that when the mathematical model determines that urbanization does not have a significant impact on environmental changes in statistical sense, it is in fact possible that the positive and negative effects of urbanization on environmental change are comparable.

\section{Research on carbon emission according to urbanization distiguish based on STIRPAT model}

As mentioned earlier, urbanization does not directly affect carbon emissions. People's social and economic activities are the direct cause of carbon emissions. In the process of urbanization, as people's agglomeration activities increase, their social and economic pattern also change, which in turn has a further impact on carbon emissions. Furthermore, in areas with different levels of urbanization, people's socio-economic pattern is naturally very different, and there is a huge difference in the level of carbon emissions among regions.

China has a vast territory with significant difference in social and economic development level among different regions. In order to make a scientific research on the influence factors and the impact of carbon emissions all over the country, a carbon emission difference analysis model based on the urbanization level is established in this paper.

\section{STIRPAT model and its extension}

STIRPAT (Stochastic Impacts by Regression on Population, Affluence, and Technology) model is a random model developed from the IPAT equation and has become the most classic model for conducting environmental impact assessments. A large amount of research work is based on it whose function expression is $I_{i}=a P_{i}^{b} A_{i}^{c} T_{i}^{d} e_{i}$ (Dietz and Rosa, 1997), where, I, P, A and T respectively denote environmental impact, population, wealth and technological level. The subscript $i$ represents each observation object. The parameter $a$ is regarded as a constant. $b, c$ and $d$ determine the influence of three factors, population, wealth and technology, on the environment, respectively. The residual item $e$ represents the social structure, system and culture that can affect the environment, and other factors that can affect human activities. In explaining the model, technology includes not only the technology itself, but also the social structure, the system, the culture, and all the other factors that can affect human activities. In practical research, STIRPAT models usually appear in logarithmic form for parameter estimation and hypothesis testing.

Based on the STIRPAT model, a series of extensions and modifications on the model can be made. First, the STIRPAT model can add other relevant factors as explanatory variables into the model, among which population structure, urbanization level and industrial structure level are the most frequently introduced variables. Maruotti (2011) and York et al. (2003) considered the variable "proportion of people between 15-65 years old" in the model. Maruotti (2011), York et al. (2003), Zhang (2013), Sadorsky (2014), Poumanyvong and Kaneko (2010), Wang et al. (2016) took into account the influencing factor of urbanization level. Second, the dummy variable can be added to 
the STIRPAT model. The parameters of the dummy variable in the model do not indicate the effect on the environmental change. The "year dummy variable" and "country dummy variable" are two common dummy variables with which the researchers distinguish the impact elasticity of carbon emissions in different years or different countries (Poumanyvong and Kaneko, 2010; Zhang et al., 2013). York et al. (2003) introduced the dummy variable "Whether the subject is in the tropics" to assess the impact of tropical regions on environmental changes. Third, the quadratic term and multiple items can also be added to the model to build nonlinear relationships between variables, which can sometimes make the model more realistic. For instance, Dietz and Rosa (1997) added a quadratic item to the population in an attempt to prove that the environmental changes and population changes are nonlinear, while York et al. (2003) added the quadratic form of per capita GDP.

\section{Classification of urbanization level}

China has a vast area and great differences in regional development. Therefore, it is necessary to classify and discriminate the urbanization status.

Population urbanization and land urbanization are two aspects of the process of urbanization. In measuring the level of urbanization, the two factors of population urbanization and land urbanization level have been comprehensively considered in this paper. Regarding the urbanization level of the population, this paper adopts the indicator of "the ratio of urban population to total population" in accordance with international practice. The research work on the level of land urbanization should include the integration of land urbanization of city and established towns. According to the stipulations of the Regulations for the Statistical Division of Urban and Rural Areas and the National New Urbanization Plan (2014-2020), the township is an important part of the scope of urbanization. At present, a large number of research work limit the scope of the inspection targets to urban areas, for example, Bai Xianchun used the land index of urban area when adjusting land factors for urbanization level (Bai, 2004) and other scholars use the area of urban built-up areas to conduct research on land factors (Table 1). In this paper, the urban and the designated town built-up area are summed up to obtain the urban built-up area, which is used to describe the level of land urbanization. The specific formula is as Equation 1:

Land urbanization level $=\frac{\text { urban built }- \text { up area }+ \text { designated town built }- \text { up area }}{\text { land survey area }}$

Table 1. Composition and data sources of urbanization classified index

\begin{tabular}{c|c|c|c}
\hline Urbanization rate & Urban built-up area & Designated town built-up area & Land survey area \\
\hline$\%$ & sq.km & sq.km & Ten thousand hectares \\
China Statistical \\
Yearbook
\end{tabular}

In this paper, lessons are drawn from the multi-index cluster analysis method of panel data based on entropy weight algorithm designed by Zheng Dachuan in 2016 to classify the level of urbanization. The specific steps are as follows: 
- Measurement of entropy weight of index (Table 2). In this paper, the most commonly used discrete degree statistics namely the standard deviation coefficient $C V_{n k}=\sigma_{n k} / \mu_{n k}$ is used to get the entropy weight result.

Table 2. Entropy weight of each urbanization index

\begin{tabular}{c|c|c}
\hline Index $\boldsymbol{k}$ & Level of population urbanization & Level of land urbanization \\
\hline Entropy weight $\alpha_{k}$ & 0.6113 & 0.3887 \\
\hline
\end{tabular}

- The Euclidean distance is used to calculate the individual distance of each index $D_{k}$ separately.

- The full distance of individual is calculated as:

$$
D=\sum_{k=1}^{K} \alpha_{k} D_{k}
$$

- Based on Equation 2, the type distance measurement is carried out by the sum of squares of deviations (Ward method), and the type of the sample is divided.

According to the results of hierarchical cluster analysis, the level of urbanization in the whole country can be divided into four categories:

- Category I: Beijing, Tianjin, Shanghai

- Category II: Liaoning, Guangdong, Jiangsu, Zhejiang

- Category III: Shanxi, Ningxia, Shaanxi, Jilin, Hubei, Hainan, Shandong, Inner Mongolia, Heilongjiang, Fujian, Chongqing, Hebei, Hunan, Jiangxi, Anhui, Qinghai, Henan, Guangxi, Sichuan and Xinjiang

- Category IV: Guizhou, Yunnan, Gansu

\section{Variable and data selection}

\section{Carbon emission accounting}

The carbon dioxide emission level is measured according to the terminal consumption of primary energy on the regional energy balance. In this paper, the total $\mathrm{CO}_{2}$ emissions from the 16 main energy sources are used as the accounting results of carbon emissions (Table 3).

Table 3. The $\mathrm{CO}_{2}$ emission coefficient of 16 energy sources (Ren, 2014)

\begin{tabular}{|c|c|c|c|c|c|c|c|c|}
\hline Energy source & $\begin{array}{l}\text { Raw } \\
\text { coal }\end{array}$ & $\begin{array}{c}\text { Cleaned } \\
\text { coal }\end{array}$ & $\begin{array}{c}\text { Other coal } \\
\text { washing }\end{array}$ & $\begin{array}{c}\text { Coal } \\
\text { briquette }\end{array}$ & Coke & Coke gas & $\begin{array}{c}\text { Blast } \\
\text { furnace gas }\end{array}$ & $\begin{array}{l}\text { Other } \\
\text { gases }\end{array}$ \\
\hline $\begin{array}{c}\text { Carbon } \\
\text { dioxide } \\
\text { emission } \\
\text { coefficient } \\
\left(\mathrm{kg}-\mathrm{CO}_{2} / \mathrm{kg} \mathrm{or}\right. \\
\left.\mathrm{kg}-\mathrm{CO}_{2} / \mathrm{m}^{3}\right)\end{array}$ & 1.9003 & 2.2829 & 0.7247 & 1.7622 & 2.8604 & 0.8469 & 0.1636 & 0.7091 \\
\hline
\end{tabular}




\begin{tabular}{c|c|c|c|c|c|c|c|c}
\hline Energy source & $\begin{array}{c}\text { Crude } \\
\text { oil }\end{array}$ & Gasoline & Kerosene & Diesel & Fuel oil & $\begin{array}{c}\text { Liquefied } \\
\text { petroleum gas }\end{array}$ & $\begin{array}{c}\text { Refinery } \\
\text { dry gas }\end{array}$ & $\begin{array}{c}\text { Natural } \\
\text { gas }\end{array}$ \\
\hline $\begin{array}{c}\text { Carbon } \\
\text { dioxide } \\
\text { emission } \\
\begin{array}{c}\text { coefficient } \\
\text { (kg-CO } / \text { /kg or } \\
\left.\text { kg-CO } \mathbf{C O}_{2} / \mathbf{m}^{3}\right)\end{array}\end{array}$ & 3.0202 & 2.9251 & 3.0179 & 3.0959 & 3.1705 & 3.1013 & 3.0119 & 2.1622 \\
\hline
\end{tabular}

\section{Population}

In the current research work, the indicators of population variables are usually expressed in terms of total population (Othman and Jafari, 2016; Yang et al., 2018). Some researchers have joined the total number of working age population. This paper holds that population density is an important factor affecting urban carbon emissions, and a higher population density will affect the degree of urban traffic congestion and have a negative impact on carbon emissions. On the other hand, high population density can promote efficient planning of the urban system and bring convenience to people's travel activities. Therefore, in this study, for the population influencing factors described, in addition to the total population, the population density index was specifically added ${ }^{1}$.

\section{Treasure}

For the factor on wealth in STIRPAT model, almost all research work is described by GDP capita (Dietz and Rosa, 1997; Poumanyvong and Kaneko, 2010; Rozanov et al., 1990), so does this paper. In order to eliminate the interference of inflation, the description of wealth in this paper especially adopts the actual GDP after deducting the price effect according to the GDP index.

\section{Technology}

Energy intensity = total energy consumption / GDP, which represents the amount of energy consumed per unit of GDP produced. The greater the value, the lower the technical level. The greater the value of energy intensity, the greater the amount of energy consumed per unit of GDP, which indicates that GDP production is more dependent on energy consumption rather than technological progress; on the contrary, it means that the higher the technological level of wealth creation, the less energy consumption can provide more output.

\section{Analysis of the factors of carbon emissions}

The principle of estimation of panel data model is included two categories: fixed effect and random effect among which the random effect RE model is the individual effect model: $y_{i t}=x_{i t}^{i} \beta+\left(\alpha_{i}+\epsilon_{i t}\right)$. For a given $i$, the mixed error term $\mu_{i}=\alpha_{i}+\epsilon_{i t}$ is related to different $\mathrm{t}$, that is, $\operatorname{Cov}\left(u_{i t}, u_{i s}\right)=\delta_{\alpha}^{2} /\left(\delta_{\alpha}^{2}+\delta_{s}^{2}\right)$, for all $\mathrm{s} \neq \mathrm{t}$.

\footnotetext{
${ }^{1}$ Population density $=$ total population $/$ total area, usually taking the unit of "person $/ \mathrm{km}^{2}$ ". In model building, we perform natural logarithm transformation on all variables to reduce the influence of heteroscedasticity. However, the population density of Qinghai Province is less than 1 in all years and cannot be converted logarithmically. Therefore, in the research process of this paper, the unit of population density is taken as "person $/ 10 \mathrm{~km}^{2}$ ".
} 
For regional economic analysis, it should be considered that there is a random effect for a certain region in a continuous period. That is to say, there is correlation between error items at different time points. This development correlation is determined by the inertia of regional social and economic development and the invariance of basic development conditions. Therefore, even if the Hausman test refuses the original hypothesis of the RE model in statistical sense, we still use the random effect model to classify the regional carbon emissions.

Based on the results of the classification of urbanization level in the whole country, the panel data analysis of four categories of provinces was conducted based on random effects in this paper. At the same time, in order to illustrate the necessity of categorical analysis, the national data are specifically estimated by a non-classified random effects model. It is easy to see from Table 4 whether classifying the level of urbanization has a great influence on the estimation result of the model.

Table 4. Comparison of estimation results based on random effects model

\begin{tabular}{c|c|c|c|c|c}
\hline & Nationwide & Category I & Category II & Category III & Category IV \\
\hline Ln (total population) & -0.1735 & -0.9151 & -0.5975 & -0.2696 & -0.2092 \\
Ln (population density) & 0.0038 & 0.2690 & 0.1324 & 0.1157 & 0.1067 \\
Ln (actual GDP) & 1.1556 & 1.3660 & 1.5469 & 1.1394 & 0.8654 \\
Ln (energy intensity) & 1.2528 & 1.6169 & 1.8601 & 1.1691 & 0.84224 \\
\hline
\end{tabular}

When estimating over the entire country, the total population and the total carbon emissions are inversely related. When the total population increases by one percentage point, $\mathrm{CO}_{2}$ emissions fall by $0.17 \%$. The population density elasticity of carbon emissions is almost zero, only $0.003 \%$. The GDP elasticity and energy intensity elasticity of carbon emissions are positive, indicating that changes in GDP and energy intensity all over the country will bring about the same direction of $\mathrm{CO}_{2}$ change.

According to different levels of urbanization, the elasticity of each variable of $\mathrm{CO}_{2}$ and the estimation of the entire country are the same under different levels of urbanization, which indicates that there is no difference in the basic direction of urbanization between different levels of urbanization. However, in terms of elasticity, there is a great difference according to the level of urbanization.

Under the background of rapid urbanization, people's awareness of the impact of carbon emissions is growing. With the increase of population, the emission of $\mathrm{CO}_{2}$ is decreasing, while with the improvement of urbanization level, the population elasticity of carbon emissions is increasing progressively. As the first category, the three largest cities of Beijing, Tianjin and Shanghai have the largest population elasticity of carbon emissions, and when the population increases by $1 \%, \mathrm{CO}_{2}$ emissions also drops by nearly $1 \%$. In the third and fourth category provinces with lower urbanization level, the population elasticity of $\mathrm{CO}_{2}$ is $0.26 \%$ and $0.21 \%$ respectively. China has become the world's second largest economy today. In China, the level of urbanization has also been greatly improved. At the same time, people's awareness of environmental protection has also been improved. The higher the level of urbanization, the deeper people's understanding of the hazards of carbon emissions, they are also more motivated to take measures to strictly control the impact of population increase on $\mathrm{CO} 2$ emissions. However, this does not prove the same conclusion under all conditions. In poor 
countries or regions, people's awareness of environmental protection is low, but the increase in population is likely to lead to an increase in carbon emissions.

The impact of population density on carbon emissions shows a positive effect at all levels of urbanization. That is, regardless of the level of urbanization, the total carbon emissions will increase correspondingly with the increase in population density, and the degree of increase will decrease with the urbanization level. In the first category of cities with the highest level of urbanization, if the population density increases by one percentage point, $\mathrm{CO}_{2}$ emissions increase by $0.26 \%$; with urbanization levels gradually decreasing, the population density elasticity of $\mathrm{CO}_{2}$ is $0.13 \%, 0.11 \%$ and $0.106 \%$ in order, indicating urban congestion caused by urbanization is a positive factor affecting $\mathrm{CO}_{2}$ emissions. Regardless of the level of urbanization, the road traffic planning and population distribution planning at this stage can not effectively reduce $\mathrm{CO}_{2}$ emissions.

With the continuous growth of the regional economy, the resulting economic activities, such as production, sales, transportation and service, have also increased, resulting in the increase of $\mathrm{CO}_{2}$ emissions, which is also verified in the model's estimation results. In particular, the growth of $\mathrm{CO}_{2}$ emissions from economic growth is more obvious in areas with relatively fast economic development, such as regions in the first and second categories. In this paper, the carbon emissions of real GDP is carried out. In these two types of regions, the real GDP elasticity of $\mathrm{CO}_{2}$ is $1.36 \%$ and $1.54 \%$, respectively, exceeding $1.13 \%$ and $0.86 \%$ of the third and fourth categories, which shows that in the more economically developed regions, the high-emission secondary industry is still driving economic growth at the current stage; at the same time, higher economic levels have led to a significant increase in people's economic activity, which has led to more emissions. In the regions of the third and fourth categories, the primary industry still accounts for a large proportion, and people's economic activities are not as good as those in developed regions. Therefore, the GDP elasticity of $\mathrm{CO}_{2}$ emissions is rather small.

Energy intensity reflects the level of energy consumption needed to create a unit of GDP, and its value reflects the production technology capabilities of a region: the higher the numerical value, the lower the technology level; conversely, it represents a higher level of technology. When estimating the energy intensity elasticity of $\mathrm{CO}_{2}$ emissions, we found that in the economically developed regions, the elastic index value is relatively large, while in the regions where the economic development level is relatively low, the elasticity level is even smaller, which means that in the economically developed regions, because the secondary industry and the tertiary industry are the pillar industries, when the level of production technology is increased and the energy intensity value is reduced, the $\mathrm{CO}_{2}$ emissions in the region will be significantly reduced, while in regions with relatively backward economies, the proportion of primary industries is still relatively large, so the reduction in $\mathrm{CO}_{2}$ emissions brought about by the increase in production technology levels is relatively limited.

\section{Conclusions}

How to reduce carbon emissions is an important issue in China at the present stage. In the process of in-depth analysis of the factors affecting carbon emissions, it is necessary to classify and study according to the level of urbanization. The discrepancy of urbanization level will inevitably lead to differences in the elasticity of carbon emission factors. Sometimes, the difference is huge. Through the empirical research in 
this paper, we can see that there are different policy focuses on measures to reduce total carbon emissions for different levels of urbanization.

For the first and second categories of regions with high level of urbanization, they have something in common in policy-making. First of all, restricting population entry does not bring about a reduction in $\mathrm{CO}_{2}$ emissions. At the same time, because of the congestion in the core aggregation areas of the population, the increase in population density and the increase in economic activity will all increase $\mathrm{CO}_{2}$ emissions. Therefore, reasonable and scientific urban development planning and population distribution planning are particularly important. Secondly, the industrial restructuring of these two categories of regions has achieved certain results, but the second industry is still the backbone of their development, so it is necessary to continue to optimize and adjust the industrial structure for the emission reduction work in these two regions. The role of technological progress in reducing $\mathrm{CO}_{2}$ emissions is quite obvious in these two regions. Therefore, encouraging and supporting the application and innovation of these two regions in technology emission reduction is the key area that the two categories of regional governments should attach importance to.

For the third and fourth categories of regions with relatively low level of urbanization, the conclusion is obvious. First, we see that the population elasticity of carbon emissions is also negative, but its absolute value is obviously smaller than the first two categories, which shows that the urban expansion of the two regions is lower because of the weak economic development, and the capacity of the cities to accommodate the new population is lower than that of the first and the second categories. Therefore, accelerating the healthy development of urban social economy is very necessary for these two categories of regions, otherwise, in the near future, the increase in population may lead to the increase in $\mathrm{CO}_{2}$ emissions. However, in terms of the population density elasticity of $\mathrm{CO}_{2}$, these two regions are advantageous because the increase in $\mathrm{CO}_{2}$ emissions caused by the increase in population density is relatively limited. However, it is still necessary to do a good job in urban planning. Second, the impact of GDP growth on $\mathrm{CO}_{2}$ emissions in these two regions is also relatively small, which seems to be inconsistent with our usual concept. As a matter of fact, the first industry accounts for a relatively large proportion in the industrial structure of these two categories of regions, so the impact of GDP growth on $\mathrm{CO}_{2}$ emissions is relatively limited. Moreover, due to income level restrictions, the economic activity of these two categories of regions will be weaker than those of the first and second categories of regions, and will result in less emissions. Similarly, in these two categories of areas, the improvement of technological progress has relatively limited impact on reducing $\mathrm{CO}_{2}$ emissions. Therefore, for these two regions, it is necessary to pay attention to improving the elasticity of technological progress in carbon emissions while optimizing the industrial structure.

In this paper, an analysis model for carbon emissions based on the level of urbanization is established. Based on the level of urbanization, the carbon emission factors and their impact elasticity under different levels of urbanization are scientifically studied in depth. The results of the study proved that "one size fits all" policy development is unable to adapt to different provinces and cities where actual conditions are not the same. This method can also be applied to other countries or regions or worldwide carbon emission studies. Different levels of urbanization will produce different conclusions. But they all prove a conclusion that it is only feasible to formulate 
targeted emission reduction policies based on the actual urbanization level of each province and city and the various factors that affect carbon emissions.

Acknowledgements. The authors gratefully acknowledge financial support from the Natural Science Foundation of Fujian Province (Fund Number: 2016J01337), Major Projects of Social Science Planning in Fuzhou (FundNumber: 2017FZA03) and Education and Scientific Research Projects of Young and Middle-Aged Teachers in Fujian Province. (Fund Number: JAS150459). All errors are our own.

\section{REFERENCES}

[1] Bai, X., Ling, K., Guo, C. et al. (2004): Urbanization in China: Horizontal estimation and international comparison. - Urban Issues 2: 23-26.

[2] Bartone, C., Bernstein, J., Leitmann, J. et al. (1994): Toward Environmental Strategies for Cities. Policy Considerations for Urban Environmental Management in Developing Countries. - The World Bank, Washington DC,

[3] Chikaraishi, M., Fujiwara, A., Kaneko, S. et al. (2015): The moderating effects of urbanization on carbon dioxide emissions: A latent class modeling approach. Technological Forecasting \& Social Change 90: 302-317.

[4] Dietz, T., Rosa, E. A. (1997): Effects of population and affluence on $\mathrm{CO}_{2}$ emissions. Proceedings of the National Academy of Sciences of the United States of America 94: 175-179.

[5] Gaigné, C., Riou, S., Thisse, J. F. (2012): Are compact cities environmentally friendly? Social Science Electronic Publishing 72: 123-136.

[6] Knox, P. L., McCarthy, L. M. (2011): Urbanization: Pearson new international edition: An introduction to urban geography. - Pearson.

[7] Lee, Y. S. (1994): Myths of Environmental Management and the Urban Poor. - In: Brennan, E. et al. (eds.) Mega-City Growth and the Future. United Nations University, Tokyo.

[8] Lu, D. (2007): Urbanization process and spatial sprawl in China. - Urban Planning Forum 4: 47-52.

[9] Marcotullio, P. J., Lee, Y. S. F. (2003): Urban environmental transitions and urban transportation systems: a comparison of the North American and Asian experience. International Development Planning Review 25: 325-354.

[10] Maruotti, A. (2011): The impact of urbanization on $\mathrm{CO}_{2}$ emissions: Evidence from developing countries. - Cesifo Working Paper 70: 1344-1353.

[11] McGranahan, G. P. et al. (2000): The citizens at risk: from urban sanitation to sustainable cities. - International Journal of Sustainability in Higher Education 24: 455-456.

[12] McGranahan, G., Songsore, J., Kjellen, M. (1996): Sustainability, Poverty and Urban Environmental Transitions. - In: Pugh, C. (ed.) Sustainability, the Environment and Urbanization. Earthscan, London, pp. 103-134.

[13] Othman, J., Jafari, Y. (2016): Identification of the key sectors that produce $\mathrm{CO}_{2}$ emissions in Malaysia: application of input-output analysis. - Carbon Management 7: 113-124.

[14] Paraschiv, M. (2012): Urbanization: an introduction to Urban Geography, third edition. Journal of Urban \& Regional Analysis 4: 1267-1268.

[15] Poumanyvong, P., Kaneko, S. (2010): Does urbanization lead to less energy use and lower $\mathrm{CO}_{2}$ emissions? A cross-country analysis. - Ecological Economics 70: 434-444.

[16] Pugh, C. (1996): Sustainability and Sustainable Cities. - In: Pugh, C. (ed.) Sustainability the Environment and Urbanization. Earthscan, London.

[17] Ren, Z. (2014): Research on Regional Differences and Emission Reduction Mechanisms of Carbon Emissions in China. - Capital University of Economics and Business, Beijing. 
[18] Rozanov, B. G., Targulian, V., Orlov, D. S. et al. (1990): The earth as transformed by human action. Global and regional changes in the biosphere over the past 300 years. Forest Ecology \& Management 55: 341-342.

[19] Sadorsky, P. (2014): The effect of urbanization on $\mathrm{CO}_{2}$, emissions in emerging economies. - Energy Economics 41: 147-153.

[20] Satterthwaite, D. (1997): Sustainable cities or cities that contribute to sustainable development? - Urban Studies 34: 1667-1691.

[21] Shahbaz, M., Loganathan, N., Muzaffar, A. T. et al. (2016): How urbanization affects $\mathrm{CO}_{2}$, emissions in Malaysia? The application of STIRPAT model. - Renewable \& Sustainable Energy Reviews 57: 83-93.

[22] Sun, C., Jin, N., Zhang, X. et al. (2013): Differences in the impact of different urbanization stages on carbon emissions. - Geographical Sciences 33: 266-272.

[23] Wang, Q., Wu, S. D., Zeng, Y. E. et al. (2016): Exploring the relationship between urbanization, energy consumption, and $\mathrm{CO}_{2}$, emissions in different provinces of China. Renewable \& Sustainable Energy Reviews 54: 1563-1579.

[24] Yang, L., Xia, H., Zhang, X. et al. (2018): What matters for carbon emissions in regional sectors? A China study of extended STIRPAT model. - Journal of Cleaner Production 180: 595-602.

[25] York, R., Rosa, E. A., Dietz, T. (2003): STIRPAT, IPAT and ImPACT: analytic tools for unpacking the driving forces of environmental impacts. - Ecological Economics 46: 351365 .

[26] Zhang, H., Wang, K., Xiang, B. (2013): A study of the differences in the effects of urbanization on $\mathrm{CO}_{2}$ emissions. - China Population, Resources and Environment 23: 152157.

[27] Zheng, D., Liu, W., Lin, Z. et al. (2016): New classification method and practical operation of China's urbanization level. - Urban Issue 9: 27-34. 